\title{
BMJ Open Tramadol and the risk of seizure: nested case-control study of US patients with employer-sponsored health benefits
}

\author{
Richard L Morrow, ${ }^{1}$ Colin R Dormuth, ${ }^{1}$ Michael Paterson, ${ }^{2}$ \\ Muhammad M Mamdani, ${ }^{3}$ Tara Gomes, ${ }^{2,4}$ David N Juurlink, ${ }^{5}$ for the Canadian Drug \\ Safety Effectiveness Research Network (CDSERN).
}

To cite: Morrow RL, Dormuth CR, Paterson M, et al. Tramadol and the risk of seizure: nested casecontrol study of US patients with employer-sponsored health benefits. BMJ Open 2019;9:e026705. doi:10.1136/ bmjopen-2018-026705

- Prepublication history and additional material for this paper are available online. To view these files, please visit the journal online (http://dx.doi org/10.1136/bmjopen-2018026705).

Received 15 September 2018 Revised 8 February 2019 Accepted 15 February 2019

Check for updates

(c) Author(s) (or their employer(s)) 2019. Re-use permitted under CC BY-NC. No commercial re-use. See rights and permissions. Published by BMJ.

For numbered affiliations see end of article.

Correspondence to

Richard L Morrow;

richard.morrow@ti.ubc.ca

\section{ABSTRACT}

Objectives Tramadol is a widely prescribed analgesic that influences both opioid and monoamine neurotransmission. While seizures have been reported with its use, the risk in clinical practice has not been well characterised. We examined risk of seizure with tramadol relative to codeine, a comparable opioid analgesic.

Design Retrospective nested case-control study. For each case, we identified up to 10 controls matched on age, sex, US state of residence and date of cohort entry $( \pm 365$ days). We calculated ORs to determine the association between seizure and exposure to tramadol, codeine ( $\geq 15 \mathrm{mg}$ ), both or neither, in the preceding 30 days. Setting Cohort of patients, who had continuous health coverage and resided in the same state for $\geq 3$ years, identified from linked administrative health data in US MarketScan databases from 2009 to 2012.

Participants We identified 96753 patients with seizure and 888540 matched controls.

Primary and secondary outcome measures In the primary analysis, we defined cases using a broad definition of seizure (based on either an outpatient physician claim for seizure disorder or a seizure-related emergency department visit or hospitalisation). In a secondary analysis, we used a more specific definition of seizure restricted to a hospital visit with a principal diagnosis of seizure.

Results In the primary analysis, we found no association between risk of seizure and exposure to tramadol compared with codeine (OR 1.03, 95\% Cl 0.93 to 1.15). However, in the secondary analysis (using a more specific definition of seizure), this association was statistically significant (OR 1.41, $95 \% \mathrm{Cl} 1.11$ to 1.79 ).

Conclusions Tramadol was not associated with an increased risk of seizure defined by inpatient and outpatient diagnoses. However, this finding was sensitive to the outcome definition used and requires further study.

\section{INTRODUCTION}

Tramadol is a widely used analgesic for both acute and chronic pain, with more than 33 million prescriptions dispensed in the USA in 2011. ${ }^{1-4}$ Canadian data from the province of Ontario indicate that tramadol was used by

\section{Strengths and limitations of this study}

A strength of this study was a large sample size.

- The study compared tramadol to codeine, a pharmacologically similar opioid, to minimise bias by indication.

- The study used a rigorous case-control design and controlled for prior diagnoses and prescription drug claims.

- A limitation was the lack of a clear, well-validated definition of seizure relevant to our study population.

- Assessment of exposure relied on prescription claims, but we had no direct measures of adherence.

$11 \%$ of individuals prescribed an opioid for pain in 2016. ${ }^{3}$

While tramadol itself inhibits reuptake of serotonin and norepinephrine, its primary metabolite (O-desmethyltramadol; 'M1') is an agonist at mu opioid receptors. Seizures emerged as a concern within a year of tramadol's 1995 market approval in the USA, based on postmarketing reports to the Food and Drug Administration. ${ }^{5}$ The drug's US label warns of the potential risk of seizures, ${ }^{6}$ which have been reported at standard doses and after overdose. $^{6-8}$

Previous observational studies have reported a possible elevated risk of seizure associated with tramadol relative to non-use, but such comparisons are prone to indication bias. ${ }^{9} 10$ One study reported no increased risk of seizures associated with tramadol relative to either other opioids or non-opioid analgesics ${ }^{10}$; however, the study excluded cases with conditions predisposing them to seizure while not treating controls in the same manner, which may have introduced bias. ${ }^{10}$ Consequently, the comparative risk of seizure with tramadol relative to other opioids remains uncertain.

We examined the association between new-onset seizures and recent use of tramadol, codeine, both or neither. We hypothesised that 


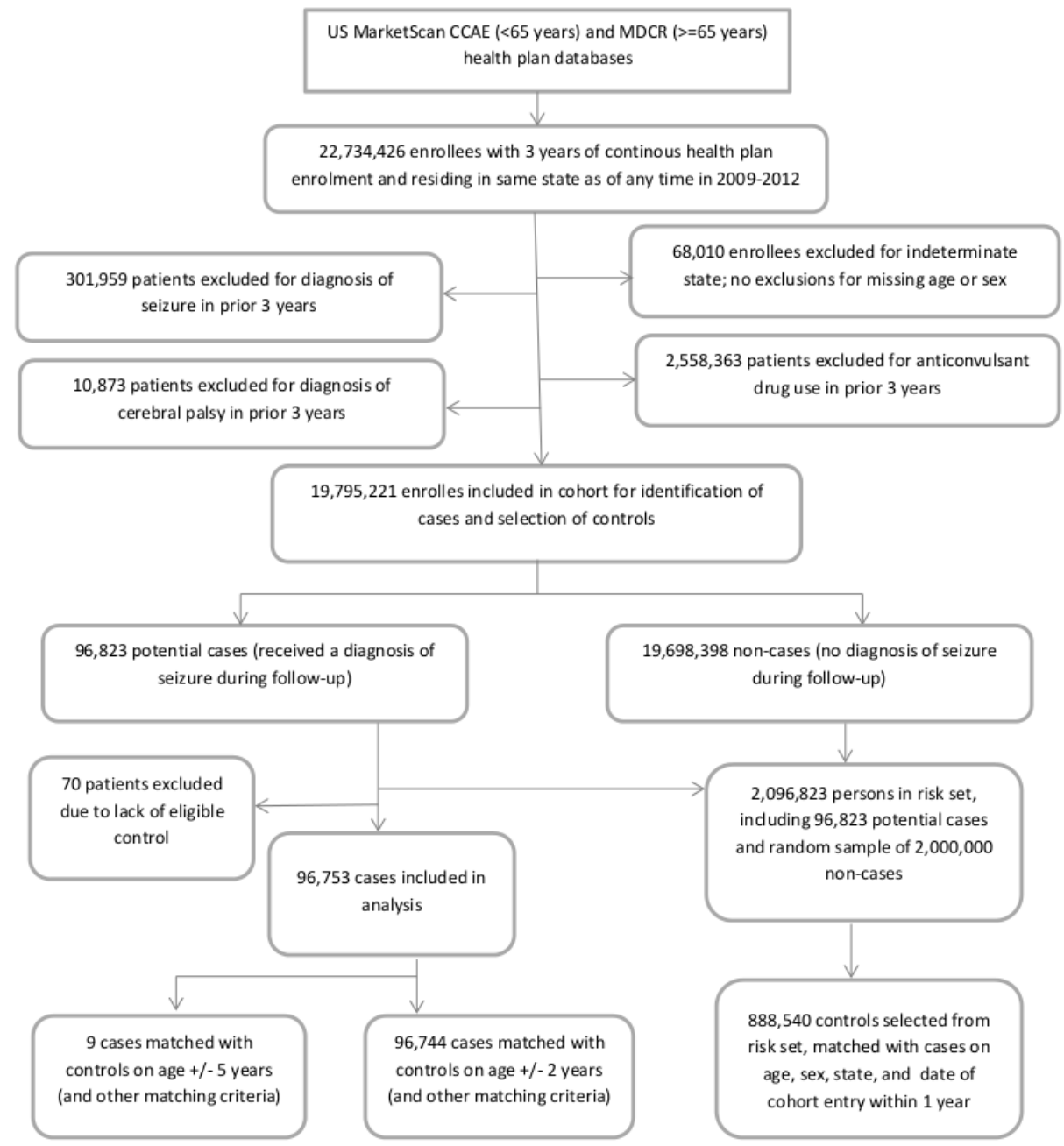

Figure 1 Study cohort and selection of cases and controls. CCAE, Commercial Claims and Encounters database; MDCR, Medicare Supplemental and Coordination of Benefits database.

tramadol would be associated with a greater risk of seizure relative to codeine.

\section{METHODS}

\section{Setting and design}

We designed a nested case-control study to examine the association between tramadol use and seizure outcomes in a cohort of US patients with private healthcare coverage. The study cohort consisted of subjects of any age who had continuous health coverage and had resided in the same state for a minimum of 3 years as of any date between 1 January 2009 and 31 December 2012.

\section{Sources of data}

We used employer-sponsored and government-sponsored health plan data from the MarketScan Commercial Claims and Encounters Database (for patients younger than 65 years) and the MarketScan Medicare Supplemental and Coordination of Benefits Database (for patients 65 years and older). These databases contain patient-level, linked data on plan enrolment, demographics, prescription drug claims, physician visits, emergency department visits and hospitalisations, and are extensively used in drug safety research. ${ }^{11-14}$

\section{Identification of cases and controls}

Subjects were eligible to be cases or controls on or after their cohort entry date, defined as the first date during the study period on which they met the study entry criteria (described above). We excluded patients with any previous diagnosis of seizure (International Classification of Diseases, version 9 (ICD-9), 780.3x), epilepsy or recurrent seizures (ICD-9, 345.xx) or cerebral palsy (ICD-9, 343.xx) assigned at a physician visit, emergency department visit or hospitalisation, as well as those dispensed an anticonvulsant drug (listed in online supplement table 1) in the 3 years preceding cohort entry. Patients remained in the cohort until the first occurrence of a physician visit, emergency department visit or hospitalisation for seizure, de-enrolment from coverage recorded in MarketScan databases, death in hospital, or the end of the study period (31 December 2012). 
Table 1 Baseline characteristics for cases and controls in analyses of tramadol and seizure

\begin{tabular}{|c|c|c|c|c|}
\hline \multirow[b]{3}{*}{ Characteristic } & \multicolumn{2}{|c|}{ (a) Primary analysis* } & \multicolumn{2}{|c|}{ (b) Secondary analysis* } \\
\hline & \multicolumn{2}{|l|}{ No (\%) of patients† } & \multicolumn{2}{|l|}{ No (\%) of patients $†$} \\
\hline & Cases $(n=96753)$ & Ctrls $\ddagger(n=888540)$ & Cases $(n=20507)$ & Ctrls $\neq(n=204531)$ \\
\hline \multicolumn{5}{|l|}{ Age (years) } \\
\hline$<18$ & $28648(29.6)$ & $284988(32.1)$ & $7204(35.1)$ & $72024(35.2)$ \\
\hline $18-29$ & $5791(6.0)$ & $57926(6.5)$ & $1517(7.4)$ & $15133(7.4)$ \\
\hline $30-39$ & $8060(8.3)$ & $80416(9.1)$ & $1797(8.8)$ & $17931(8.8)$ \\
\hline $40-49$ & $11972(12.4)$ & $119667(13.5)$ & 2556 (12.5) & $25593(12.5)$ \\
\hline $50-59$ & $15250(15.8)$ & 152985 (17.2) & $2865(14.0)$ & $28691(14.0)$ \\
\hline $60-64$ & $4373(4.5)$ & $42830(4.8)$ & $766(3.7)$ & 7607 (3.7) \\
\hline$\geq 65$ & $22659(23.4)$ & $149728(16.9)$ & $3802(18.5)$ & $37552(18.4)$ \\
\hline \multicolumn{5}{|l|}{ Sex } \\
\hline Women & $48468(50.1)$ & $448537(50.5)$ & $9366(45.7)$ & $93367(45.6)$ \\
\hline Men & 48285 (49.9) & $440003(49.5)$ & $11141(54.3)$ & $111164(54.4)$ \\
\hline \multicolumn{5}{|l|}{ Diagnoses§ } \\
\hline Stroke & $5106(5.3)$ & $18155(2.0)$ & $901(4.4)$ & $4034(2.0)$ \\
\hline $\begin{array}{l}\text { Cerebrovascular } \\
\text { diseaseף }\end{array}$ & $3836(4.0)$ & $10541(1.2)$ & $702(3.4)$ & $2211(1.1)$ \\
\hline Previous brain injury & $955(1.0)$ & $3284(0.4)$ & $207(1.0)$ & $787(0.4)$ \\
\hline Hypoxaemia & $550(0.6)$ & $2481(0.3)$ & $100(0.5)$ & $559(0.3)$ \\
\hline Infection & $4201(4.3)$ & 29730 (3.3) & $856(4.2)$ & $7121(3.5)$ \\
\hline Alzheimer's disease & $1180(1.2)$ & $3237(0.4)$ & $301(1.5)$ & $765(0.4)$ \\
\hline Depression & $4960(5.1)$ & $23088(2.6)$ & $1070(5.2)$ & $4781(2.3)$ \\
\hline Anxiety & $3273(3.4)$ & $16117(1.8)$ & $659(3.2)$ & $3429(1.7)$ \\
\hline Head injury & $3938(4.1)$ & $18919(2.1)$ & $911(4.4)$ & $4633(2.3)$ \\
\hline Malnutrition & $356(0.4)$ & $1088(0.1)$ & $77(0.4)$ & $168(0.1)$ \\
\hline Diabetes & $11968(12.4)$ & $72603(8.2)$ & 2267 (11.1) & $15442(7.5)$ \\
\hline Cancer & 16354 (16.9) & 122709 (13.8) & $2862(14.0)$ & 26459 (12.9) \\
\hline \multicolumn{5}{|l|}{ Hospitalisations§ } \\
\hline None & $85648(88.5)$ & $838310(94.3)$ & $18247(89.0)$ & 193405 (94.6) \\
\hline One & $8747(9.0)$ & $43044(4.8)$ & $1745(8.5)$ & $9650(4.7)$ \\
\hline Two & $1750(1.8)$ & $5791(0.7)$ & $362(1.8)$ & $1191(0.6)$ \\
\hline Three or more & $608(0.6)$ & $1395(0.2)$ & $153(0.7)$ & $285(0.1)$ \\
\hline \multicolumn{5}{|l|}{ Drug utilisation§ } \\
\hline $\begin{array}{l}\text { No of drugs, median } \\
\text { (IQR) }\end{array}$ & $4(1,8)$ & $4(1,6)$ & $4(1,7)$ & $3(1,6)$ \\
\hline Bupropion & $1924(2.0)$ & $10535(1.2)$ & $437(2.1)$ & $2058(1.0)$ \\
\hline Other antidepressant & $14320(14.8)$ & 75005 (8.4) & 2798 (13.6) & $15522(7.6)$ \\
\hline Anticholinergics & 4794 (5.0) & 29900 (3.4) & $830(4.0)$ & 6663 (3.3) \\
\hline
\end{tabular}

${ }^{*}$ The primary analysis used a sensitive definition of seizure, while the secondary analysis used a more specific definition of seizure. †Except where indicated.

$\ddagger$ Ctrls $=$ controls.

§In year prior to cohort entry.

ๆCerebrovascular disease other than stroke.

Despite several validation studies, ${ }^{15} 16$ a clear, validated algorithm for seizure relevant to our study population was not available. We therefore employed both a broad definition of seizure (including outpatient diagnoses as well as emergency department and inpatient diagnoses) in the primary analysis, and a more specific definition of 
Table 2 Primary analysis of association between tramadol use and seizure (sensitive definition)

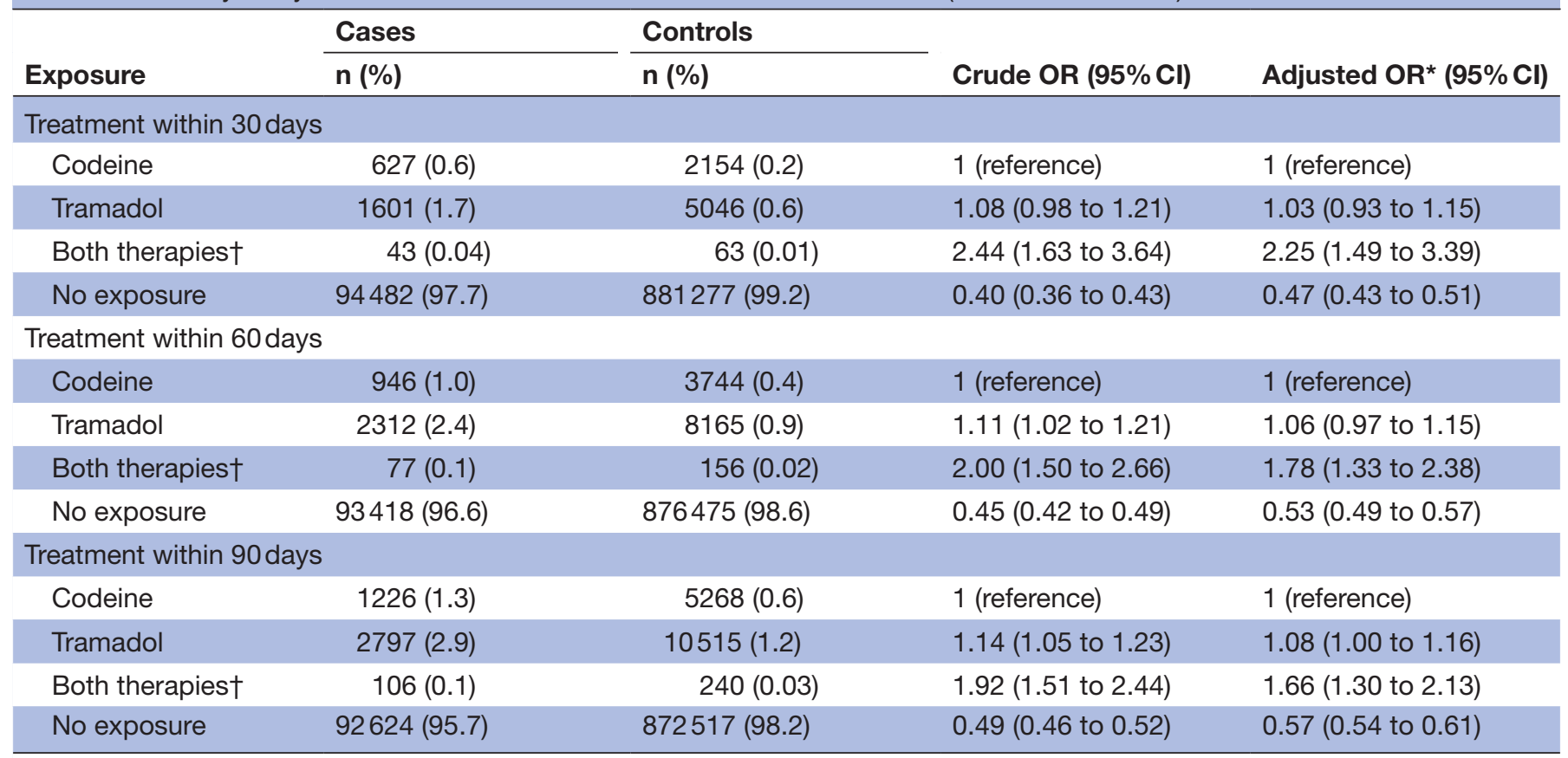

*Adjusted for comorbidities and health services use in the year prior to cohort entry: history of stroke, other cerebrovascular disease, brain injury, hypoxaemia, infection, Alzheimer's disease, depression, anxiety, head injury, malnutrition, diabetes or cancer (in hospital or outpatient diagnoses); the number of drugs dispensed; the number of hospitalisations ( $0,1,2$ or $\geq 3)$; and receipt of one or more prescriptions of bupropion, other antidepressants or anticholinergics.

†Patients with exposure at any dosage to both tramadol and codeine were categorised under 'both therapies'.

seizure (restricted to emergency department visits and hospital admissions) in the secondary analysis. In the primary analysis, we defined cases of seizure as the first physician visit, emergency room visit or hospital admission with a diagnosis for convulsions (ICD-9, 780.3x) or for epilepsy or recurrent seizures (ICD-9, 345.xx). In the secondary analysis, we restricted our case definition to seizures involving an emergency department visit or hospital admission (ICD-9, 345.xx or 780.3x) in the first and primary diagnostic fields, respectively, selecting controls using the same approach applied in the primary analysis. We defined the date of first occurrence of seizure as a case's index date.

For each case, we randomly selected up to 10 controls from the study cohort, matching on age, sex, US state of residence and date of cohort entry (within 1 year). The initial calliper for matching on age was \pm 2 years, but for cases with no matches we widened the calliper to \pm 5 years to avoid losing cases. We assigned controls the same index date as their corresponding case. Study subjects who became cases were permitted to serve as controls at an earlier time, and no subjects were permitted to serve as a control more than once.

\section{Statistical analysis}

We examined the association between new-onset seizures and exposure to tramadol, codeine (the reference drug), both tramadol and codeine, or neither drug in the 30 days preceding the index date. We defined exposure to tramadol as any prescription claim for tramadol dispensed in the 30 days exposure window, and defined exposure to codeine as any prescription for codeine during the same period. However, we included only codeine formulations of $15 \mathrm{mg}$ or more to exclude codeine use for milder pain or other indications. In both cases, we limited the formulations to tablet or capsule. We used codeine as the comparator because, like tramadol, it is widely perceived as a weak opioid and is converted to an active opioid by cytochrome P450 enzyme 2D6.

We used conditional logistic regression to estimate ORs and 95\% CIs for the association between seizure and exposure to tramadol, codeine, both or neither in the 30 days preceding the index date. To test the robustness of our findings, we performed sensitivity analyses using exposure periods of 60 and 90 days. We adjusted for several potential confounding factors assessed in the year prior to cohort entry, including history of stroke, other cerebrovascular disease, head injury, brain injury, hypoxaemia, infection, Alzheimer's disease, depression, anxiety, malnutrition, diabetes and cancer, the number of hospitalisations, number of unique drugs dispensed, and one or more prescription drug claims for bupropion, other antidepressants and anticholinergics. The specific drugs and diagnosis codes we used to define these covariates are listed in online supplement tables 1 and 2, respectively. Statistical analyses were conducted with SAS, V.9.3.

Finally, we conducted an exploratory analysis of seizure with additional tramadol and codeine exposure categories based on average daily dose of medication dispensed in 
Table 3 Secondary analysis of association between tramadol use and seizure (specific definition)

\begin{tabular}{|c|c|c|c|c|}
\hline \multirow[b]{2}{*}{ Exposure } & \multirow{2}{*}{$\begin{array}{l}\text { Cases } \\
\mathrm{n}(\%)\end{array}$} & \multirow{2}{*}{$\begin{array}{l}\text { Controls } \\
\mathrm{n}(\%)\end{array}$} & \multirow[b]{2}{*}{ Crude OR (95\% Cl) } & \multirow[b]{2}{*}{ Adjusted OR* $(95 \% \mathrm{Cl})$} \\
\hline & & & & \\
\hline \multicolumn{5}{|c|}{ Treatment within 30 days } \\
\hline Tramadol & 405 (2.0) & $1111(0.5)$ & 1.48 (1.18 to 1.87$)$ & 1.41 (1.11 to 1.79$)$ \\
\hline Both therapies $\dagger$ & $14(0.1)$ & $10(0.005)$ & 5.97 (2.58 to 13.79$)$ & 5.79 (2.42 to 13.83$)$ \\
\hline Codeine & $175(0.9)$ & $818(0.4)$ & 1 (reference) & 1 (reference) \\
\hline Tramadol & $545(2.7)$ & $1777(0.9)$ & 1.45 (1.20 to 1.76$)$ & 1.40 (1.15 to 1.70$)$ \\
\hline Both therapies $†$ & $21(0.1)$ & $27(0.01)$ & 3.76 (2.07 to 6.80$)$ & 3.42 (1.85 to 6.35$)$ \\
\hline No exposure & 19766 (96.4) & $201909(98.7)$ & 0.46 (0.39 to 0.54$)$ & 0.52 (0.44 to 0.62$)$ \\
\hline Both therapies $\dagger$ & $30(0.1)$ & $50(0.02)$ & 3.20 (1.99 to 5.15$)$ & 2.84 (1.73 to 4.67$)$ \\
\hline No exposure & 19626 (95.7) & 201041 (98.3) & 0.51 (0.44 to 0.59$)$ & 0.59 (0.51 to 0.68$)$ \\
\hline
\end{tabular}

*Adjusted for comorbidities and health services use in the year prior to cohort entry: history of stroke, other cerebrovascular disease, brain injury, hypoxaemia, infection, Alzheimer's disease, depression, anxiety, head injury, malnutrition, diabetes or cancer (in hospital or outpatient diagnoses); the number of drugs dispensed; the number of hospitalisations $(0,1,2$ or $\geq 3)$; and receipt of one or more prescriptions of bupropion, other antidepressants or anticholinergics.

†Patients with exposure at any dosage to both tramadol and codeine were categorised under 'both therapies'.

the 90 days prior to the index date, to investigate whether a dose-response relationship exists between tramadol and seizure. We used codeine at a daily dosage of $<180 \mathrm{mg}$ as a reference category. We examined tramadol daily doses of $<200 \mathrm{mg}, 200$ to $<400 \mathrm{mg}$ and $\geq 400 \mathrm{mg}$, and codeine daily doses of 180 to $<360 \mathrm{mg}$ and $\geq 360 \mathrm{mg}$. We conducted separate dose-response analyses for seizure defined with a sensitive definition and with a specific definition. As a sensitivity analysis, we conducted an additional doseresponse analysis which used codeine $\leq 120 \mathrm{mg}$ as a reference category and examined tramadol daily doses of $\leq 150 \mathrm{mg},>150$ to $250 \mathrm{mg}$ and $>250 \mathrm{mg}$, and codeine daily doses of $>120$ to $200 \mathrm{mg}$ and $>200 \mathrm{mg}$.

\section{Patient and public involvement}

We used secondary data from administrative health databases to conduct our analyses. Patients and members of the public were not involved with the developing research questions or with study design.

\section{RESULTS}

We identified 19795221 individuals meeting our inclusion criteria (figure 1). From within this cohort, in the primary analysis we identified 96753 cases, matching them with 888540 controls (median age, 42 years; IQR $13-58)$. We excluded $70(0.1 \%)$ potential cases due to lack of an eligible control. In the secondary analysis using the more specific case definition, we matched 20507 cases with 204531 controls (median age, 38 years; IQR
$12-57)$, while $16(<0.1 \%)$ potential cases were excluded due to lack of an eligible control. Baseline characteristics are shown in table 1 . As expected, in both analyses, cases were more likely to have comorbidities, more hospitalisations and be prescribed medications relative to controls.

In the primary analysis, we observed no increased risk of seizures among patients who received tramadol compared with codeine alone (adjusted OR 1.03, 95\% CI 0.93 to 1.15 ) (table 2). However, patients treated with both tramadol and codeine experienced a markedly elevated risk of seizures relative to those treated with codeine alone (adjusted OR 2.25, 95\% CI 1.49 to 3.39), while unexposed patients experienced a lower risk (adjusted OR $0.47,95 \%$ CI 0.43 to 0.51 ) (table 2 ).

In the secondary analysis using the more specific case definition for seizure, we found that patients receiving tramadol faced a $41 \%$ higher risk of seizures compared with those receiving codeine alone (adjusted OR 1.41, 95\% CI 1.11 to 1.79 ) (table 3). Patients treated with both tramadol and codeine experienced a markedly higher risk of seizures relative to those treated with codeine alone (adjusted OR 5.79, 95\% CI 2.42 to 13.83), while unexposed patients experienced a lower risk (adjusted OR $0.45,95 \%$ CI 0.36 to 0.55 ). Analyses using exposure periods of 60 or 90 days produced similar results (tables 2 and 3 ).

In our analyses of a dose-response relationship between seizure and tramadol exposure in the 90 days prior to the index date, we observed no significant association 
Table 4 Dose-response analysis of association between tramadol use and seizure

\begin{tabular}{|c|c|c|c|c|}
\hline \multirow{2}{*}{$\begin{array}{l}\text { Exposure within } 90 \text { days } \\
\text { (daily dose) }^{\star}\end{array}$} & \multirow{2}{*}{$\begin{array}{l}\text { Cases } \\
\mathrm{n}(\%) \\
\end{array}$} & \multirow{2}{*}{$\begin{array}{l}\text { Controls } \\
\mathrm{n}(\%)\end{array}$} & \multirow{2}{*}{$\begin{array}{l}\text { Crude OR } \\
(95 \% \mathrm{Cl})\end{array}$} & \multirow{2}{*}{$\begin{array}{l}\text { Adjusted OR† } \\
(95 \% \mathrm{Cl})\end{array}$} \\
\hline & & & & \\
\hline \multicolumn{5}{|c|}{$\begin{array}{l}\text { (a) Primary analysis (sensitive seizure } \\
\text { definition): }\end{array}$} \\
\hline Tramadol, <200 mg & $1130(1.17)$ & $4212(0.47)$ & 1.10 (0.98 to 1.22$)$ & 1.04 (0.93 to 1.16$)$ \\
\hline Tramadol, 200 to $<400 \mathrm{mg}$ & $1440(1.49)$ & $5466(0.62)$ & 1.12 (1.01 to 1.25$)$ & 1.09 (0.98 to 1.22$)$ \\
\hline Tramadol, $\geq 400 \mathrm{mg}$ & $227(0.23)$ & $837(0.09)$ & 1.23 (1.04 to 1.46$)$ & 1.16 (0.97 to 1.38$)$ \\
\hline Codeine, $<180 \mathrm{mg}$ & $620(0.64)$ & $2577(0.29)$ & 1 (reference) & 1 (reference) \\
\hline Codeine, 180 to $<360 \mathrm{mg}$ & $513(0.53)$ & $2325(0.26)$ & 0.95 (0.83 to 1.08$)$ & 0.98 (0.86 to 1.12$)$ \\
\hline Codeine, $\geq 360 \mathrm{mg}$ & $93(0.10)$ & $366(0.04)$ & 1.11 (0.87 to 1.42$)$ & 1.09 (0.85 to 1.40$)$ \\
\hline Both therapies $\ddagger$ & $106(0.11)$ & $240(0.03)$ & 1.89 (1.48 to 2.42$)$ & 1.66 (1.29 to 2.14$)$ \\
\hline No exposure & 92624 (95.73) & 872517 (98.20) & 0.48 (0.44 to 0.53$)$ & 0.57 (0.52 to 0.62$)$ \\
\hline
\end{tabular}

(b) Secondary analysis (specific seizure

definition):

\begin{tabular}{lrrll}
\hline Tramadol, $<200 \mathrm{mg}$ & $251(1.22)$ & $920(0.45)$ & $1.57(1.22$ to 2.03$)$ & $1.52(1.17$ to 1.97$)$ \\
\hline Tramadol, 200 to $<400 \mathrm{mg}$ & $324(1.58)$ & $1204(0.59)$ & $1.54(1.21$ to 1.97$)$ & $1.54(1.20$ to 1.98$)$ \\
\hline Tramadol, $\geq 400 \mathrm{mg}$ & $58(0.28)$ & $169(0.08)$ & $1.94(1.35$ to 2.80$)$ & $1.95(1.34$ to 2.84$)$ \\
\hline Codeine, $<180 \mathrm{mg}$ & $101(0.49)$ & $573(0.28)$ & 1 (reference) & 1 (reference) \\
Codeine, 180 to $<360 \mathrm{mg}$ & $97(0.47)$ & $494(0.24)$ & $1.11(0.82$ to 1.50$)$ & $1.16(0.85$ to 1.58$)$ \\
Codeine, $\geq 360 \mathrm{mg}$ & $20(0.10)$ & $80(0.04)$ & $1.43(0.84$ to 2.43$)$ & $1.39(0.80$ to 2.42$)$ \\
Both therapies $\neq$ & $30(0.15)$ & $50(0.02)$ & $3.45(2.09$ to 5.68$)$ & $3.12(1.85$ to 5.26$)$ \\
No exposure & $19626(95.70)$ & $201041(98.29)$ & $0.55(0.45$ to 0.68$)$ & $0.65(0.52$ to 0.80$)$ \\
\hline
\end{tabular}

${ }^{*}$ Average daily dose dispensed during the 90 days exposure window.

†Adjusted for comorbidities and health services use in the year prior to cohort entry: history of stroke, other cerebrovascular disease, brain injury, hypoxaemia, infection, Alzheimer's disease, depression, anxiety, head injury, malnutrition, diabetes or cancer (in hospital or outpatient diagnoses); the number of drugs dispensed; the number of hospitalisations $(0,1,2$ or $\geq 3)$; and receipt of one or more prescriptions of bupropion, other antidepressants or anticholinergics.

$\ddagger$ Patients with exposure at any dosage to both tramadol and codeine were categorised under 'both therapies'.

between tramadol or codeine and seizure when we used a sensitive definition of seizure (table 4 ). When we used a specific definition of seizure, we observed a higher risk of seizure for the highest level of tramadol exposure (OR $1.95,95 \%$ CI 1.34 to 2.84, for tramadol $\geq 400 \mathrm{mg}$ daily) than for lower daily doses of tramadol, when each was compared with codeine $<180 \mathrm{mg}$ daily. However, the risk of seizure was similar for low and moderate daily doses of tramadol (OR 1.52, 95\% CI 1.17 to 1.97 , for tramadol $<200 \mathrm{mg}$ daily, and OR $1.54,95 \% \mathrm{CI}$ 1.20 to 1.98 , for tramadol 200 to $<400 \mathrm{mg}$ daily). We observed no significant association between higher daily doses of codeine and seizure when compared with codeine $<180 \mathrm{mg}$ daily; however, higher daily doses of codeine were correlated with higher point estimates of the risk of seizure when a specific definition of seizure was used (OR 1.16, 95\% CI 0.85 to 1.58 , for codeine 180 to $<360 \mathrm{mg}$ daily, and OR $1.39,95 \%$ CI 0.80 to 2.42 , for codeine $\geq 360 \mathrm{mg}$ daily). Our sensitivity analysis using different dose categories produced a similar pattern of results (online supplement table 3 ).

\section{DISCUSSION}

We found that tramadol was not associated with a higher risk of seizure than codeine when using a broad definition of seizure. However, when a more specific definition of seizure was used, tramadol was associated with a $41 \%$ increase in risk. A possible explanation for these discrepant results is that some patients were misclassified in the primary analysis due to a lack of specificity in the outcome definition, but not in a way that differed between tramadol and codeine users. This type of outcome misclassification would typically bias an effect estimate toward a null effect. ${ }^{17}$ Therefore, although tramadol may be associated with an increased risk of seizure, this finding was sensitive to the outcome definition used.

Two previous epidemiological studies using administrative health data reported a possible increased risk of seizure related to tramadol use, ${ }^{9}{ }^{10}$ but these findings were based on comparisons with non-use and would almost certainly be subject to indication bias. One study reported that seizure risk associated with tramadol use was not elevated relative to other opioid or non-opioid analgesics, ${ }^{10}$ but the study was likely subject to selection 
bias because the authors excluded cases with conditions predisposing them to seizure without treating controls in the same way.

The current study compared tramadol to codeine. In comparison with previous studies, our analyses of tramadol versus codeine use may provide estimates with greater validity by minimising selection biases, including indication bias. Codeine appears to increase risk of seizure compared with non-use, but subjects prescribed neither analgesic likely have better health status on average. If codeine were associated with seizure, this would bias our comparisons of tramadol and codeine toward a null result. While some case reports have suggested that codeine may be associated with seizure, ${ }^{18} 19$ there is a lack of rigorous epidemiological studies on this issue. We used codeine as a comparator both to limit indication bias and provide a clinically relevant comparison.

We found that tramadol was associated with a higher risk of seizure at the highest level of tramadol exposure than at low or moderate daily doses, compared with codeine, in a dose-response analysis using a specific definition of seizure. This provides some evidence of a dose-response relationship between tramadol and seizure, although the risk of seizure did not differ for low and moderate daily doses of tramadol when each was compared with codeine. It is not clear whether the increased risk for the highest tramadol exposure category was due to the higher dose of tramadol or to possibly to an increased susceptibility to seizure among patients receiving a high daily dose. Although no significant association was found between risk of seizure and higher doses of codeine relative to low-dose codeine, the correlation of higher doses of codeine with higher point estimates of the risk of seizure suggest a possible dose-response relationship which may represent indication bias.

Some limitations of our study merit emphasis. We used a broad seizure definition including outpatient diagnoses in our primary analysis, but found an association between tramadol and seizure only in our secondary analysis using a definition of seizure restricted to emergency department and inpatient diagnoses. It is possible that our primary outcome was biased toward the null due to misclassification bias, but this is unclear due to the lack of a well-validated definition of seizure in the literature. ${ }^{15}$ In addition, we compared tramadol and codeine to limit indication bias, but it is possible that patients treated with tramadol differed from those treated with codeine in unmeasurable ways. Although we adjusted for several potential confounding factors in our analyses, patients treated with tramadol and codeine might differ in disease severity. The prevalence of alcohol dependence or opioid use disorder might also differ among treatment groups, but these factors are under-reported in administrative health data and were not adjusted for in our study. Finally, our assessment of exposure relied on prescription claims, and we have no direct measures of adherence. However, this applies equally to both tramadol and codeine.

\section{CONCLUSIONS}

In this study of US patients with employer-sponsored and government-sponsored health benefits, we found that tramadol in comparison to codeine was not associated with increased risk of seizure defined by inpatient and outpatient diagnoses. However, this finding was sensitive to the outcome definition used and requires further study. While seizures are an uncommon adverse event, this outcome has considerable importance to public health due to the high prevalence of use of tramadol and other opioid and non-opioid analgesic medications, and the consequences of seizure activity (including falls, head injury and loss of driving privileges). Additional research is needed to investigate the potential association between tramadol use and seizures.

\section{Author affiliations}

${ }^{1}$ Department of Anesthesiology, Pharmacology and Therapeutics, University of British Columbia, Victoria, British Columbia, Canada

${ }^{2}$ Institute for Clinical Evaluative Sciences, Toronto, Ontario, Canada

${ }^{3}$ Applied Health Research Centre, Li Ka Shing Knowledge Institute, St. Michael's Hospital, Toronto, Ontario, Canada

${ }^{4} \mathrm{Li}$ Ka Shing Knowledge Institute, Toronto, Ontario, Canada

${ }^{5}$ Clinical Pharmacology and Toxicology, Sunnybrook Health Sciences Centre, Toronto, Ontario, Canada

Collaborators Members of the Canadian Drug Safety and Effectiveness ResearchNetwork: David N. Juurlink (chair), Institute for Clinical Evaluative Sciences,Toronto, Ont.; Colin R. Dormuth, University of British Columbia, Vancouver, BC;Chelsea Hellings (program coordinator), Institute for Clinical EvaluativeSciences, Toronto, Ont.; Anita L. Kozyrskyj, University of Manitoba, Winnipeg,Man.; Muhammad M. Mamdani, St. Michael's Hospital, Toronto, Ont.; Yola Moride, Universitéde Montréal, Montréal, Que.; J. Michael Paterson, Institute for ClinicalEvaluative Sciences, Toronto, Ont.; Colette Raymond, Manitoba Centre for HealthPolicy, University of Manitoba, Winnipeg, Man.; and Robyn Tamblyn, McGillUniversity, Montréal, Que.

Contributors RLM had full access to all of the data in the study and takes responsibility for the integrity of the data and the accuracy of the data analysis. He was also involved in the drafting of the manuscript. DNJ, CRD and RLM: study concept and design; statistical analysis; administrative, technical or material support. All authors: acquisition, analysis or interpretation of data; critical revision of the manuscript for important intellectual content. DNJ, MP, MMM and TG: obtaining funding. DNJ and CRD: study supervision.

Funding The Canadian Drug Safety Effectiveness Research Network was funded by an Emerging Team Grant from ClHR (grant no. ETG-92247).

Disclaimer The funder had no role in the design and conduct of the study; collection, management, analysis or interpretation of the data; or in the preparation, review, or approval of the manuscript.

Competing interests MMM has served on advisory boards for NovoNordisk and Allergan and received an honorarium for giving a talk on research methods to staff at Celgene.

\section{Patient consent for publication Not required.}

Ethics approval The University of British Columbia Clinical Research Ethics Board reviewed and approved this research project.

Provenance and peer review Not commissioned; externally peer reviewed.

Data sharing statement The authors do not have permission to share data from this study.

Open access This is an open access article distributed in accordance with the Creative Commons Attribution Non Commercial (CC BY-NC 4.0) license, which permits others to distribute, remix, adapt, build upon this work non-commercially, and license their derivative works on different terms, provided the original work is properly cited, appropriate credit is given, any changes made indicated, and the use is non-commercial. See: http:// creativecommons.org/licenses/by-nc/4.0/. 


\section{REFERENCES}

1. Manchikanti L, Helm S, Fellows B, et al. Opioid epidemic in the United States. Pain Physician 2012;15:ES9-38.

2. Chevalier P, Smulders M, Chavoshi S, et al. A description of clinical characteristics and treatment patterns observed within prescribed opioid users in Germany and the UK. Pain Manag 2014;4:267-76.

3. Gomes T, Pasricha S, Martins D, et al. Behind the prescriptions: a snapshot of opioid use across all ontarians. Toronto: Ontario Drug Policy Research Network, 2017.

4. Hollingworth SA, Symons M, Khatun M, et al. Prescribing databases can be used to monitor trends in opioid analgesic prescribing in Australia. Aust N Z J Public Health 2013;37:132-8.

5. Kahn LH, Alderfer RJ, Graham DJ. Seizures reported with tramadol. JAMA 1997;278:1661.

6. ULTRAM®. ULTRAM® tramadol hydrochloride) tablets. http://www. accessdata.fda.gov/drugsatfda_docs/label/2009/020281s032s033lbl. pdf (Accessed 12th Jun 2016).

7. Spiller HA, Gorman SE, Villalobos D, et al. Prospective multicenter evaluation of tramadol exposure. J Toxicol Clin Toxicol 1997;35:361-4.

8. Beyaz SG, Sonbahar T, Bayar F, et al. Seizures associated with low-dose tramadol for chronic pain treatment. Anesth Essays Res 2016;10:376-8.

9. Gardner JS, Blough D, Drinkard CR, et al. Tramadol and seizures: a surveillance study in a managed care population. Pharmacotherapy 2000;20:1423-31.
10. Gasse C, Derby L, Vasilakis-Scaramozza C, et al. Incidence of first-time idiopathic seizures in users of tramadol. Pharmacotherapy 2000;20:629-34.

11. Azoulay L, Filion KB, Platt RW, et al. Association between incretinbased drugs and the risk of acute pancreatitis. JAMA Intern Med 2016;176:1464-73.

12. Dormuth $\mathrm{CR}$, Filion KB, Paterson JM, et al. Higher potency statins and the risk of new diabetes: multicentre, observational study of administrative databases. BMJ 2014;348:g3244.

13. Alhusayen RO, Juurlink DN, Mamdani MM, et al. Isotretinoin use and the risk of inflammatory bowel disease: a population-based cohort study. J Invest Dermatol 2013;133:907-12.

14. Zhou $F$, Harpaz $R$, Jumaan $A O$, et al. Impact of varicella vaccination on health care utilization. JAMA 2005;294:797-802.

15. Kee VR, Gilchrist B, Granner MA, et al. A systematic review of validated methods for identifying seizures, convulsions, or epilepsy using administrative and claims data. Pharmacoepidemiol Drug Sa 2012;21 Suppl 1:183-93.

16. Thyagarajan V, Su S, Gee J, et al. Identification of seizures among adults and children following influenza vaccination using health insurance claims data. Vaccine 2013;31:5997-6002.

17. Rothman KJ, Greenland S, Lash TL. Validity in epidemiologic studies. Modern epidemiology. 3rd edn. Philadelphia: Lippincott Williams and Wilkins, 2008:128-47.

18. Zolezzi M, Al Mohaimeed SA. Seizures with intravenous codeine phosphate. Ann Pharmacother 2001;35:1211-3.

19. Kuo SC, Lin YC, Kao SM, et al. Probable codeine phosphateinduced seizures. Ann Pharmacother 2004;38:1848-51. 